\title{
A influência de Maurício Tragtenberg na obra da primeira geração de pesquisadores nos Estudos Organizacionais críticos brasileiros
}

\author{
Maurício Tragtenberg's influence on the work of the first generation of researchers in \\ Brazilian critical organizational studies
}

\author{
André Luis Marra do Amorim ${ }^{1}$ \\ Universidade Federal do Paraná, Programa de Pós- Graduação em Administração, Curitiba - PR, Brasil \\ Camila Brüning ${ }^{2}$ \\ Universidade Federal do Paraná, Programa de Pós- Graduação em Administração, Curitiba - PR, Brasil
}

\begin{abstract}
Resumo
Influenciar um campo acadêmico não é um papel desempenhado por muitos pesquisadores. No caso dos Estudos Organizacionais brasileiros, esse papel foi desempenhado por poucos. Maurício Tragtenberg é reconhecido como precursor dos Estudos Organizacionais críticos brasileiros, sua influência pode ser percebida em diversas temáticas de pesquisa. Nesse sentido, este artigo analisa a influência das categorias temáticas de Tragtenberg na produção acadêmica da chamada primeira geração de autores críticos em Estudos Organizacionais no Brasil, quais sejam, Fernando Prestes Motta, José Henrique de Faria e Fernando Coutinho Garcia, que foram citados pelo próprio Tragtenberg como o grupo que recebeu diretamente sua influência. Para tanto, foi analisado o levantamento das produções acadêmicas desses autores. A pesquisa demonstrou que as categorias tragtenbergianas estão presentes nas obras dos três pesquisadores abordados e que eles foram historicamente contemporâneos em sua produção acadêmica, constituindo um grupo coeso, que pode ser indicado como a primeira geração de pesquisadores em Estudos Organizacionais críticos brasileiros.
\end{abstract}

Palavra-chave: Maurício Tragtenberg. Estudos Organizacionais. Estudos Críticos.

\begin{abstract}
Influencing an academic field is not a role played by many researchers. In the case of Brazilian Organizational Studies, this role has been played by very few people. Maurício Tragtenberg is recognized as the precursor of Brazilian critical Organizational Studies, his influence may be noticed in several research themes. Thus, this article analyzes the influence of Tragtenberg's thematic categories on the academic production of the so-called first generation of critical authors in Organizational Studies in Brazil, namely, Fernando Prestes Motta, José Henrique de Faria, and Fernando Coutinho Garcia, who have been cited by Tragtenberg himself as the group that directly received his influence. For this, the survey of academic works by these authors was analyzed. The research found out that Tragtenberg's categories are observed in works by the three researchers approached and they were historically contemporary in their academic production,
\end{abstract}

Artigo submetido em 28 de fevereiro de 2014 e aceito para publicação em 11 de julho de 2014.

\section{DOI: http://dx.doi.org/10.1590/1679-395117185}

${ }^{1}$ Mestre em administração pela Universidade Federal do Paraná; Doutorando do Programa de Pós- Graduação em Administração na Universidade Federal do Paraná. Endereço: Av. Prof. Lothario Meissner, $632-2^{\circ}$ andar - Jardim Botânico, CEP 80210-170, Curitiba - PR, Brasil. E-mail: andreluismarra@gmail.com

${ }^{2}$ Mestre em administração pela Universidade Federal do Paraná; Doutoranda do Programa de Pós- Graduação em Administração na Universidade Federal do Paraná. Endereço: Av. Prof. Lothario Meissner, 632 - 2o andar - Jardim Botânico, CEP 80210-170, Curitiba R, Brasil. E-mail: camila.bruning@gmail.com 
constituting a cohesive group, which may be pointed out as the first generation of researchers in Brazilian critical Organizational Studies.

Keywords: Maurício Tragtenberg. Organizational Studies. Critical Studies.

\section{Introdução}

Sem o desenvolvimento de uma perspectiva teórica de análise capaz de propor uma ponderação sobre o tipo de pesquisa e os conhecimentos produzidos e de apontar aspectos ideológicos existentes nos estudos científicos sobre organizações, a área dos Estudos Organizacionais brasileiros não apresentaria todos os componentes necessários para ser considerada consistente. Nesse sentido, pode-se afirmar que a crítica possui seu lugar no campo das pesquisas científicas e cumpre o papel social de demonstrar que outra perspectiva existe, não pode ser ignorada e que é possível pensar de modo diferente do mainstream na área da Administração.

José Henrique de Faria (2009), ao escrever sobre o estado da arte da produção crítica em Estudos Organizacionais no Brasil, apresenta uma classificação composta por quatro diferentes abordagens consideradas críticas, que serve para localizar o tópico analisado neste artigo: 1) Teoria Crítica - que se baseia nas produções da escola de Frankfurt; 2) Teoria Crítica em Estudos Organizacionais - que se baseia no marxismo, utiliza mas não se limita aos estudos da escola de Frankfurt, podendo adotar abordagens interdisciplinares, como a psicossociologia clínica, e sendo, também, conhecida como economia política do poder em Estudos Organizacionais; 3) Critical Management Studies - conduzidos principalmente por Alvesson, Willmott e Deetz, tratam-se de estudos críticos em gestão na perspectiva da gestão; e, finalmente, 4) Análises Críticas em Estudos Organizacionais - que concentrariam as análises críticas não marxistas e não frankfurtianas que estudam as organizações do ponto de vista das relações de poder.

Paes de Paula, Maranhão, Barreto et al. (2010) apresentam classificação semelhante quando debatem a autonomia da produção crítica brasileira em Estudos Organizacionais em relação aos Critical Management Studies, afirmando que autores seminais como Guerreiro Ramos (que começou a publicar nos anos 1950) e Maurício Tragtenberg (com publicações já da década de 1970) publicavam seus estudos antes mesmo da área de Critical Management Studies se organizar nos Estados Unidos e na Europa. Além disso, os estudos nacionais também possuíam orientações epistemológicas distintas: Guerreiro Ramos adotou uma postura não marxista e não frankfurtiana de alinhamento entre fenomenologia e existencialismo (FARIA, 2009) e Maurício Tragtenberg seguiu uma abordagem marxista heterodoxa, permeada pelo anarquismo.

Neste artigo, ratifica-se essa influência de Guerreiro Ramos e de Maurício Tragtenberg como precursores da teoria crítica em Estudos Organizacionais no Brasil, já anteriormente defendida por outros autores. Porém, procura-se enfatizar a influência de Maurício Tragtenberg na produção acadêmica do que aqui se defende como a primeira geração da Teoria Crítica em Estudos Organizacionais no Brasil, de inspiração marxista/anarquista.

Vale considerar que um campo de estudos, em qualquer área das ciências, não se consolida por meio do trabalho de um único pesquisador, mas, sim, por um conjunto de pesquisadores. Isso ocorre por diversas questões, entre elas, é necessário considerar o fator temporal, que demanda a sustentação de um conjunto temático mais ou menos coeso e com força suficiente de exposição em determinado campo científico para que venha a ser considerado uma corrente consistente pelos pesquisadores pares que constituem aquele campo, logicamente, assumindo uma constituição comum de campo científico.

A contribuição deste artigo para os Estudos Organizacionais consiste em resgatar materialmente a formação dessa linha de estudos que se solidificou sob a influência de Maurício Tragtenberg, enquanto intelectual precursor de Estudos Organizacionais críticos marxistas/anarquistas no Brasil. Para examinar essa 
ascendência acadêmica, delimita-se o estudo na primeira geração de autores cujas obras foram diretamente influenciadas por Tragtenberg: Fernando Prestes Motta, José Henrique de Faria e Fernando Coutinho Garcia.

Para tanto, são apresentadas, em linhas gerais, as principais categorias temáticas trabalhadas por Maurício Tragtenberg, que serão utilizadas para avaliar o desenvolvimento histórico da produção acadêmica dos três pesquisadores citados.

O argumento defendido ao longo deste estudo é que esses três autores devem ser considerados a primeira geração da teoria crítica em Estudos Organizacionais brasileiros sob influência da obra tragtenbergiana, pois eles constituem um grupo relativamente coeso que desenvolveu suas teses e pesquisas sob a influência da obra e do convívio com o professor Maurício Tragtenberg, como declarado pelo próprio:

Concluindo, penso que um professor que consegue a mudança de paradigmas numa área e fecundar uma obra como a de Fernando Prestes Motta, José Henrique [de] Faria, na teoria administrativa, Fernando Coutinho Garcia, da UFMG, conseguiu seu objetivo. Isso porque, segundo os clássicos chineses, influenciar é ter poder (TRAGTENBERG, 1991, p. 9).

Este artigo está organizado da seguinte maneira: a primeira seção apresenta as noções gerais das principais categorias trabalhadas por Tragtenberg. Em seguida, apresenta-se o caminho metodológico que orientou o trabalho de análise aqui desenvolvido. Na terceira apresenta-se a análise dos dados coletados. Por fim, são apresentadas as considerações finais. De saída, é importante salientar que a escolha das categorias utilizadas aqui é fruto de uma síntese analítica da obra de Tragtenberg. Desse modo, por ser uma escolha, pode não abranger totalmente a vasta produção acadêmica do autor.

\section{Referencial Teórico}

Maurício Tragtenberg é considerado precursor da área de Teoria Crítica em Estudos Organizacionais. Segundo Faria (2009), sob a influência de Tragtenberg a área de Estudos Organizacionais fixou-se nos referenciais weberianos, marxistas e anarquistas, não tendo inspiração direta em Adorno, Horkheimer, Marcuse, Fromm ou em Habermas, autores da escola de Frankfurt. Faria (2009) afirma que Tragtenberg traçou uma linha própria de pensamento, dirigindo seus estudos às questões da burocracia, do poder e da dominação, em suas diversas formas de manifestação, sob a ótica do marxismo-anarquismo. Em Burocracia e ideologia, Tragtenberg (1974) já utiliza aquilo que ficou marcado como característica de seu pensamento: a interdisciplinaridade com coerência epistemológica que cria as bases para uma transformação no campo de Estudos Organizacionais (FARIA, 2009).

Como professor, pesquisador e colega, Maurício Tragtenberg é descrito como intelectual autodidata que vivia na prática os ideais que embasavam suas teorias, tendo, em boa parte de sua produção, tratado dos dilemas da classe trabalhadora e da educação (SILVA e MARRACH, 2001). Recusando toda forma de dominação, dedicou-se à crítica à violência, à denúncia ao burocratismo e ao apontamento das contradições da ideologia gerencialista predominante na teoria geral da Administração (FARIA, 2009).

O tema central de Tragtenberg é o poder, sendo influenciado por Marx e Weber. A influência de Marx se demonstra em sua produção acadêmica pelo uso, entre outros, dos conceitos de classes sociais, divisão do trabalho, relações de produção, forças produtivas, alienação, sendo também clara a presença marxista pela utilização do método dialético que utiliza em suas reflexões. A influência de Weber se demonstra, principalmente, na busca em relação aos seus estudos sobre burocracia e autoridade. Sua postura assumidamente heterodoxa na produção acadêmica e sua dedicação ao tema poder o fez recorrer também a pensadores como Althusser e Foucault, a autores anarquistas e socialistas libertários, como as importantes influências de Kropotkin (relacionadas ao "comunismo libertário"), Bakunin (relacionadas à defesa de que as energias revolucionárias devem centrar-se na destruição das "coisas", inclusive o Estado, e não os 
indivíduos), Trotski (relacionadas às noções de "degenerescência do Estado", "degenerescência burocrática das organizações operárias", "democracia operária"), bem como à psicologia social de Freud e a autores literários como Tolstói e Dostoiévski, cujos romances foram importantes para iniciar sua caminhada nas obras dos anarquistas, socialistas libertários, e, também, na compreensão de Marx (MENEGHETTI, 2009).

A obra de Maurício Tragtenberg $(1967 ; 1974 ; 1980 ; 1986 ; 1991)$ é marcada pela questão do poder. Temas como divisão do trabalho, dominação, controle social, ideologia, burocracia e educação permeiam suas análises, que, localizadas historicamente, focalizavam o modo de produção capitalista e seus mecanismos de exploração. Sua teoria e sua prática sempre foram no sentido da crítica da dominação e na busca pela emancipação da classe trabalhadora, pelo resgate de sua autonomia e de sua condição humana. Embora todos esses temas sejam inter-relacionados, para tornar mais didática a exposição aqui apresentada e facilitar as análises realizadas neste estudo, a seguir são apresentadas as visões de Maurício Tragtenberg em relação aos temas: 1) poder e controle; 2) burocracia e organizações; 3) ideologia e autonomia; e 4) crítica à forma de produção capitalista.

\section{Poder e Controle}

Defende-se neste artigo que Maurício Tragtenberg é o precursor dos estudos referentes às formas de dominação e controle no trabalho, a partir das análises que apresentou sobre o desenvolvimento das teorias da Administração. Para o autor, o fenômeno originário das diferenças sociais presentes no modo de produção capitalista é a divisão do trabalho. Decorrente disso, Tragtenberg utiliza o conceito marxista de classes sociais e, consequentemente, o de luta de classes para analisar a disputa pela dominação de um grupo sobre o outro (MENEGHETTI, 2009).

A obra de Tragtenberg versa sobre diferentes enfoques sobre o poder, tratando da dominação e do controle social de uma classe social por outra classe social. Por compreender que esse núcleo fundamental constitui e dá forma aos instrumentos de poder e de dominação, Tragtenberg dedica uma parte considerável de sua obra acadêmica à produção de textos que enfoquem e analisem as manifestações da burocracia, da ideologia e das "tecnologias de gestão" (FARIA, 1992) desenvolvidas pela teoria administrativa.

\section{Burocracia e Organizações}

O conceito de burocracia utilizado por Tragtenberg é influenciado pela teoria weberiana. Segundo Tragtenberg (1974), para Weber, burocracia é uma forma de poder, com possibilidade de ser igualado à organização. Desse modo, o autor entende a burocracia como um sistema racional, decorrente da divisão do trabalho, cuja orientação declarada é a da eficiência e da técnica. A relação direta entre divisão do trabalho e burocracia ocorre porque a última é consequência da complexidade que a divisão técnica do trabalho atinge no modo de produção atual.

Para esclarecer a manutenção da coerência teórica na utilização conjunta das obras de Weber e Marx, Tragtenberg (1974) afirma a necessidade de pensar e refletir criticamente sobre a obra de Weber, absorvendo sua contribuição com a ressalva de considerar que a burocracia estudada por Weber não é um tipo ideal, em si mesma, mas, sim, um fenômeno social/organizacional marcado por determinadas características históricas em que o capitalismo é a forma de produção dominante.

A ênfase de Tragtenberg (1974) no estudo da burocracia, assim como entendia que era a ênfase de Weber, não se encontra no estudo das virtudes organizacionais da burocracia, mas, sim, nas formas de resistência perante o avanço burocrático. Além disso, suas críticas procuram denunciar os diversos desdobramentos que a divisão do trabalho produz dentro das organizações burocráticas. Nesse sentido, é notória a atenção 
despendida em sua obra à evolução das tecnologias de gestão como forma de contínua adaptação do modo de produção capitalista, com objetivo de harmonizar a divisão técnica do trabalho, a burocracia, o planejamento às mudanças externas às organizações (MENEGHETTI, 2009).

A burocracia, para Tragtenberg, é um instrumento que materializa a dominação do capital. Ao formalizar e tornar impessoais as relações que ocorrem nos ambientes organizacionais, ela atua no sentido oposto ao da autonomia e na medida em que aumenta seu nível de complexidade, também aumenta a dificuldade para a autonomia tanto individual como coletiva. Por tudo isso, Tragtenberg se posicionava contrariamente a qualquer forma de burocratização que impedisse a autonomia dos sujeitos.

\section{Ideologia e Autonomia}

Burocracia e ideologia são conceitos inter-relacionados na obra de Tragtenberg (1974). Segundo o autor, a partir do momento que ocorre a divisão do trabalho entre os que planejam e os que executam as atividades, a separação entre trabalho manual e trabalho intelectual contém implicações ideológicas, morais, culturais e políticas que passam a ser sedimentadas por meio da burocracia para garantir a permanência da separação entre os que executam e os que decidem (MENEGHETTI, 2009).

O entendimento de Tragtenberg considera que a ideologia seja uma manifestação presente em todas as épocas históricas, porém, sua manifestação em organizações burocráticas exerce a função de disciplinamento e de controle social. Além disso, essas funções podem reproduzir-se de forma tanto intencional como não intencional e por vias tanto objetivas como subjetivas (MENEGHETTI, 2009). Nesse sentido, é interessante reproduzir a emblemática declaração de Tragtenberg (2004) sobre como é melancólico observar que a ideologia do poder consiste na mentira. Isto é, "o poder apresenta um discurso autonomista e uma prática de dependência" (TRAGTENBERG, 2004, p. 112).

A possibilidade de autonomia dentro de um contexto marcado pela complexidade da burocracia, e de sua correspondente ideologia, estaria para Tragtenberg também na organização coletiva dos trabalhadores. Assim, o autor defendia a autogestão como necessária para transformações no plano econômico, da base ao topo. Para o autor, portanto, a autonomia deveria ser construída a partir da organização dos trabalhadores na base de produção, tendo defendido que as comissões de fábrica poderiam representar o plano mais efetivo dessa organização (MENEGHETTI, 2009).

\section{Produção Capitalista}

Ao entender que ideologia e burocracia só podem ser estudadas enquanto localizadas histórica e materialmente, Tragtenberg constrói seus argumentos a partir do estudo das formas concretas que a produção capitalista assume. Nesse sentido, o autor apresenta uma crítica da Teoria Geral da Administração (TGA), demonstrando como, por exemplo, Taylorismo, Fordismo, Teoria Comportamental, Escola das Relações Humanas e Abordagem Sistêmica das Organizações são adaptações de uma mesma lógica de exploração da mais-valia gerada pelo trabalhador, caracterizando a TGA como uma ideologia que reforça a dominação e o controle social do capital (TRAGTENBERG, 1989).

Para Tragtenberg (1974), esse processo de ideologização da teoria administrativa ocorre porque autores como, por exemplo, Taylor, Fayol e Mayo, são estudados sem a devida contextualização histórica e sem esclarecimentos sobre os interesses relativos às formas de gestão desenvolvidas e defendidas por esses autores (TRAGTENBERG, 1974). 
Segundo Antunes (2001), Tragtenberg também foi um crítico pioneiro das novas formas de gestão da produção, principalmente em relação ao Toyotismo, entendendo a evolução das tecnologias de gestão da produção desde a era da Administração clássica até as adaptações e aperfeiçoamentos atuais, como ajustes técnicos realizados pelo modo de produção capitalista sobre os mecanismos de exploração da mais-valia e do controle social. A investigação e a denúncia desses mecanismos para os principais envolvidos nesse processo (a classe trabalhadora) foram uma constante na atuação de Tragtenberg (ANTUNES, 2001).

As visões de Maurício Tragtenberg sobre poder, controle, burocracia, ideologia, autonomia e evolução das tecnologias de gestão das organizações capitalistas apresentam as características relatadas nos parágrafos anteriores. Não é objetivo deste estudo apresentar uma extensa revisão da obra do autor, que pode ser consultada em outros estudos, busca-se apenas elucidar seu entendimento sobre os pontos sinalizados para que seja possível verificar sua influência na obra de outros três pesquisadores que tiveram contato próximo não só com sua obra, mas, também, com sua pessoa: Fernando Prestes Motta, José Henrique de Faria e Fernando Coutinho Garcia, como será explanado a seguir.

\section{Procedimento Metodológico}

A proposta deste estudo é delimitar a abordagem aos pesquisadores Fernando Prestes Motta, José Henrique de Faria e Fernando Coutinho Garcia, entendidos como a primeira geração da teoria crítica em Estudos Organizacionais brasileiros que recebeu influência tragtenbergiana. Com a finalidade de materializar e possibilizar a visualização dessa influência, propõe-se analisar o desenvolvimento histórico das categorias conceituais trabalhadas por Tragtenberg nas publicações acadêmico-científicas desses três autores. Nesse sentido, o escopo metodológico envolve a descrição do levantamento, das classificações do material utilizado na análise e das limitações inerentes ao trabalho realizado.

Para investigar o desenvolvimento histórico foi necessário buscar uma base de dados que apresentasse a evolução histórica das publicações que seriam avaliadas. Desse modo, a base escolhida foi o sistema mantido pelo Conselho Nacional de Desenvolvimento Científico e Tecnológico (CNPq), denominado Plataforma Lattes. Essa base foi escolhida por apresentar uma organização histórica e, também, por ser tradicionalmente utilizada pelos pesquisadores nacionais como um sistema de organização de publicações e atividades acadêmicas.

Foram analisados artigos publicados em periódicos, trabalhos apresentados em congresso, livros e capítulos de livros. Aqui se aponta uma limitação do método utilizado: a Plataforma Lattes depende da alimentação intencional dos pesquisadores, portanto, não representa um sistema de indexação automático. Desse modo, os dados existentes na base foram inseridos pelos usuários e diversas outras publicações e atividades acadêmicas podem não ter sido incluídas no sistema. Dessa forma, este artigo não almeja abranger todas as atividades acadêmicas divulgadas ou publicadas pelos pesquisadores e as análises se limitam aos dados disponíveis na Plataforma Lattes.

Após esse primeiro levantamento das produções de Maurício Tragtenberg e, posteriormente, de Fernando Prestes Motta, José Henrique de Faria e Fernando Coutinho Garcia, procedeu-se a uma classificação temática, isto é, de acordo com os temas trabalhados nos textos. Essa classificação temática foi realizada a partir do material disponível para consulta imediata: preferencialmente, acessou-se a publicação na íntegra, porém, quando se tratavam de publicações de circulação restrita ou paga foram analisados apenas os resumos e títulos. Essa opção metodológica teve o objetivo principal de evitar que publicações relacionadas no perfil dos autores na Plataforma Lattes fossem desconsideradas da análise somente por conta de dificuldades de acesso ao material completo.

A classificação primária gerou um conjunto de 10 temas: 1) Poder - textos que tratam do conceito de poder e relações de poder; 2) Controle - textos que tratam das práticas de controle; 3) Organização - textos que 
tratam das temáticas relacionadas ao ambiente organizacional; 4) Burocracia - textos que analisam especificamente as organizações burocráticas e suas práticas; 5) Trabalho - publicações que avaliam organização do trabalho e relações de trabalho; 6) Gestão - publicações que analisam as práticas gerenciais em ambientes organizacionais; 7) Teoria Crítica - material que se relaciona especificamente aos temas ligados à escola de Frankfurt; 8) Epistemologia/Metodologia - textos que tratam de questões epistemológicas e metodológicas que envolvem a pesquisa crítica em Estudos Organizacionais; 9) Tragtenberg - material que se relaciona diretamente com os trabalhos e as categorias tratadas pelo autor; e 10) Outros - categoria que agrega textos com temáticas isoladas ou sem relação com os conteúdos tratados nas outras categorias. Cada tema procurou representar a temática principal trabalhada nas publicações analisadas.

O primeiro conjunto temático foi reclassificado em 5 dimensões agregadoras para facilitar a leitura didática dos temas trabalhados por Tragtenberg: 1) Poder e Controle (poder, controle); 2) Burocracia e Organizações (burocracia, organização); 3) Autonomia e Ideologia (trabalho e gestão); 4) Produção Capitalista (teoria crítica); e 5) Outros (metodologia científica, temas isolados e sem relação com as categorias tratadas neste artigo). Esta segunda classificação foi utilizada para o tratamento dos dados levantados e para as análises realizadas aqui. Assim, os dados foram classificados por autor, por data e por categorias para demonstrar sua evolução histórica. O tratamento dos dados se deu pela incidência de ocorrência absoluta, ou seja, cada publicação recebeu pelo menos uma, classificação (pontuou pelo menos em um tema) de acordo com a temática predominante e o total de classificações foi somado para ser utilizado nas análises desenvolvidas.

Ressalta-se que essa categorização atende exclusivamente a objetivos didáticos e formais da manifestação escrita da língua portuguesa. Na realidade concreta, essas categorias se apresentam na totalidade dos fenômenos observados e de maneira contraditória, não havendo separação apriorística de onde termina uma e começa a outra.

É importante sinalizar, ainda, que as publicações não seguem a mesma ordem cronológica para os três autores, portanto, quando não foram encontradas publicações de determinado ano para um autor, ela recebeu o indicador "zero", como um modo de equalização para que os anos analisados para todos os pesquisadores avaliados. Além disso, também é válido ressaltar que o pesquisador Fernando Prestes Motta apresenta as publicações zeradas para os anos posteriores ao seu falecimento; isso não significa que sua contribuição tenha sido, de alguma maneira, inferior à de José Henrique de Faria e Fernando Coutinho Garcia.

Além das limitações já apresentadas, considera-se que são inerentes ao trabalho realizado as limitações cognitivas, temporais e instrumentais dos próprios pesquisadores que realizam a análise apresentada nesta pesquisa.

\section{Resultados e Análise dos Dados}

A análise dos dados coletados apresenta a seguinte estrutura: em primeiro lugar, os dados combinados por autor e data são demonstrados para a discussão da evolução histórica e da contemporaneidade dos autores analisados; em seguida, são analisadas a evolução das categorias temáticas por autor isolado; por fim, demonstra-se a evolução histórica das categorias temáticas de Tragtenberg quando combinadas as produções dos três autores analisados. Esses recortes foram utilizados buscando estabelecer uma aproximação do desdobramento histórico das categorias teóricas de Tragtenberg, considerando que a construção de um campo teórico consistente é influenciada por diversos fatores, entre eles a continuidade histórica de temas abordados.

No total, as publicações avaliadas receberam 388 classificações de categorias temáticas. Esse número contém duplicações, pois uma publicação pode receber duas ou mais classificações ao mesmo tempo. A distribuição das classificações deu-se da seguinte maneira: 82 para Prestes Motta, 121 para Garcia e 185 para Faria. Mais uma vez, vale ressaltar que os números não representam a intenção de classificar o pesquisador mais 
importante ou mais produtivo. Longe disso, busca-se apenas demonstrar o comportamento que os dados apresentaram a partir das análises realizadas.

Fernando Prestes Motta, José Henrique de Faria e Fernando Coutinho Garcia, de acordo com os dados levantados, podem ser considerados contemporâneos em termos de produção científico-acadêmica. Embora o primeiro tenha iniciado sua produção cerca de 10 anos antes dos outros, os temas abordados giravam em torno de conteúdos organizacionais de caráter não crítico, como, por exemplo, estruturalismo, funcionalismo e behaviorismo. Portanto, se for considerada a produção de caráter crítico analisado, os três autores iniciam a publicação de seus estudos quase simultaneamente, no final da década de 1970. A Gráfico 1 apresenta a evolução das publicações dos três autores.

\section{Gráfico 1}

\section{Evolução quantitativa das publicações dos três autores analisados.}

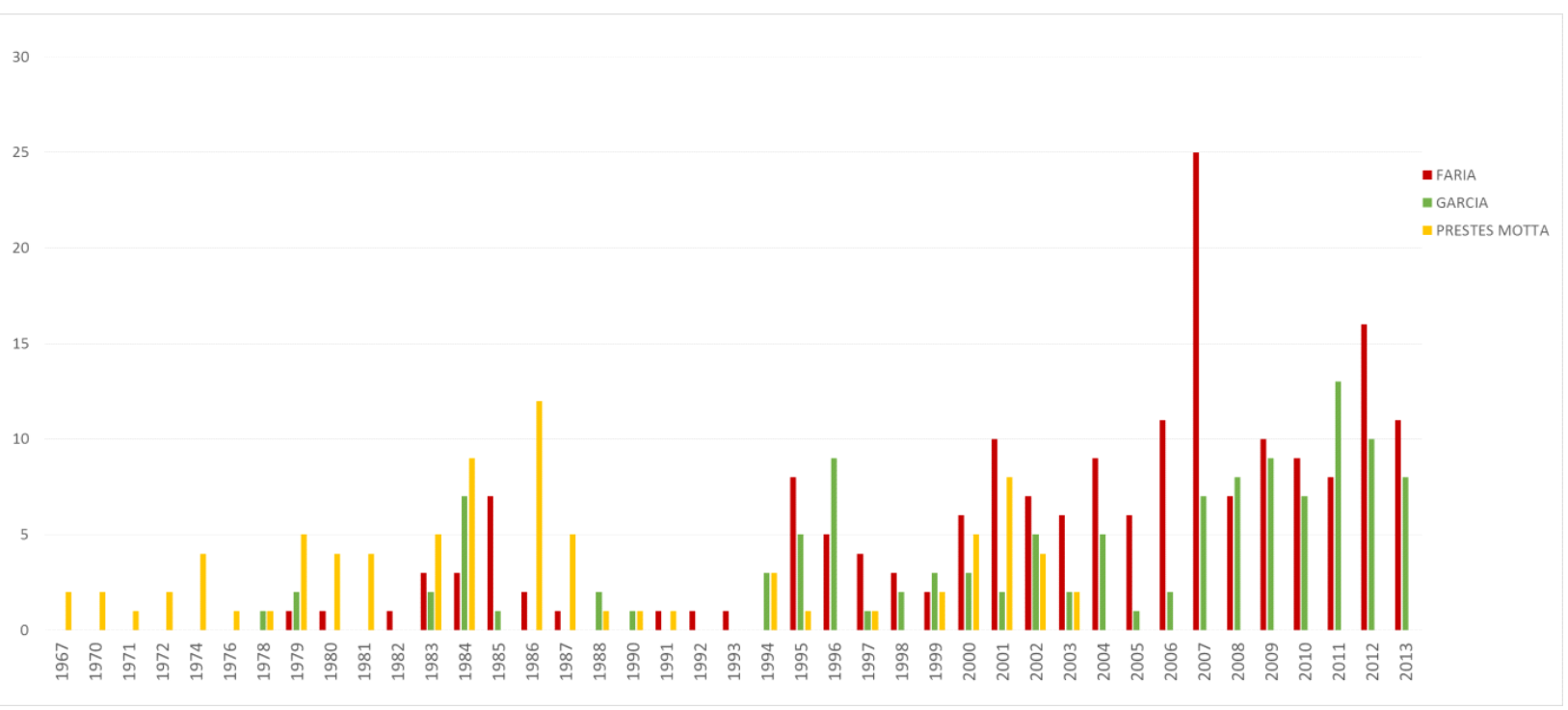

Fonte: Elaborada pelos autores.

Como demonstrado nas análises temáticas, os trabalhos publicados pelos três autores, a partir de 1979, abordam de modo gradativamente mais concentrado as categorias trabalhadas por Tragtenberg sinalizadas neste artigo. Essa situação pode indicar que é a partir desse ano que a influência de Tragtenberg sobre os três pesquisadores analisados começa a se fazer sentir em sua produção acadêmica. $O$ fato desse acontecimento apresentar uma data mais ou menos demarcada pode demonstrar que os três autores foram contemporâneos nos estudos relacionados às temáticas críticas. Essa indicação de contemporaneidade será alvo de investigações futuras durante a realização de entrevistas qualitativas com José Henrique de Faria e Fernando Coutinho Garcia. No entanto, de modo preliminar, ela reforça a menção conjunta que o próprio Tragtenberg fez aos três pesquisadores.

As análises sobre a evolução das categorias temáticas por autor são apresentadas a seguir. A intenção desta seção é demonstrar como as categorias trabalhadas por Tragtenberg permeiam o desenvolvimento teórico dos três autores. No entanto, a análise mais aprofundada sobre a orientação do conteúdo atribuída a cada publicação ainda será objeto de investigações futuras, pois não se pode deixar de considerar que a classificação em determinada categoria tragtenbergiana seja condição suficiente para atribuir a mesma orientação aos trabalhos desenvolvidos pelos três pesquisadores em análise neste artigo. A Gráfico 2 apresenta a evolução histórica das publicações de Prestes Motta. 


\section{Gráfico 2.}

\section{Evolução histórica em Prestes Motta.}

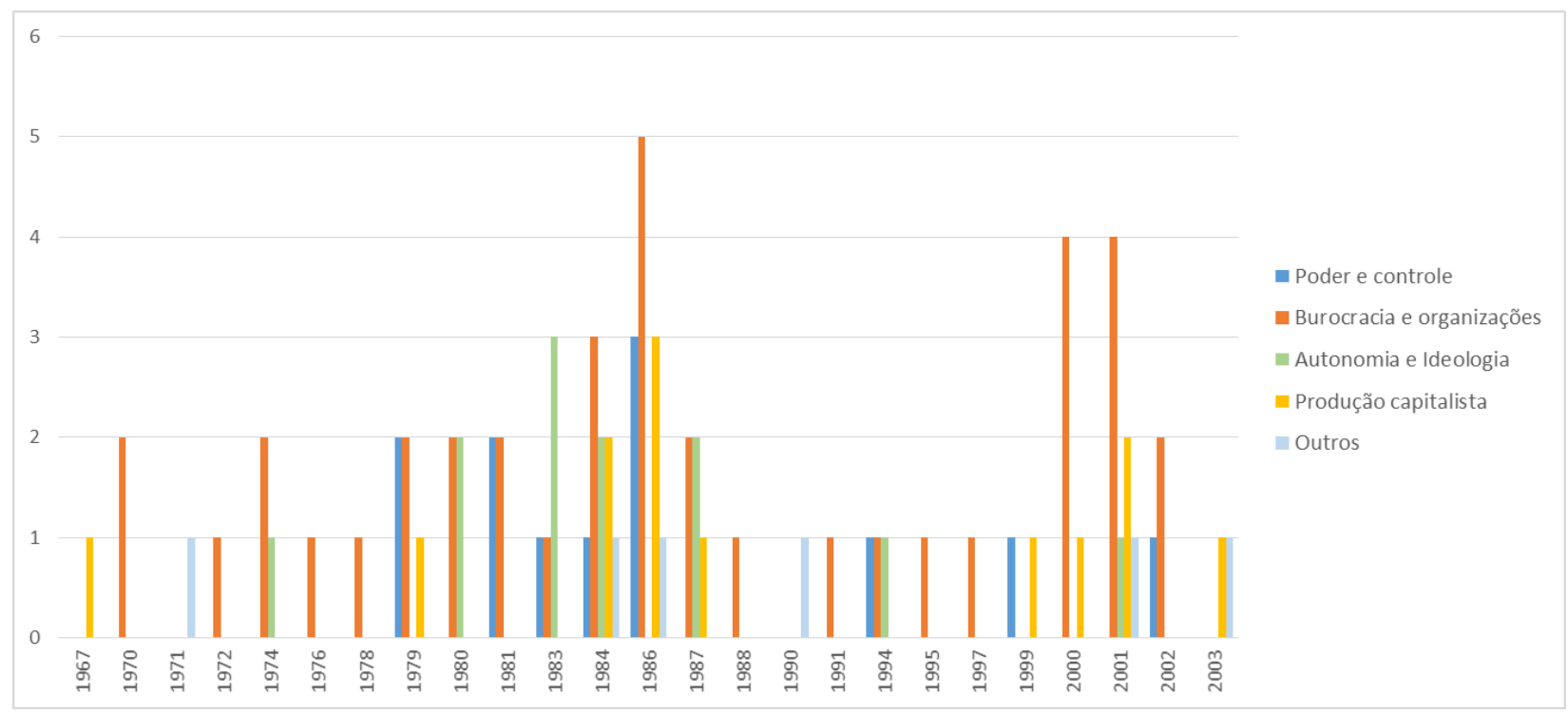

Fonte: Elaborada pelos autores.

Historicamente, a produção acadêmica de Prestes Motta se inicia cerca de 10 anos antes da produção dos outros autores analisados neste artigo, no entanto, as temáticas trabalhadas se referem, em geral, a estudos iniciais que foram realizados a partir de referências funcionalistas e estruturalistas. Vários desses artigos compõem o livro Teoria geral da Administração: uma introdução (MOTTA, 2001). Assim como os outros dois pesquisadores, a orientação crítica nas publicações ganha volume a partir de 1979. Esse aspecto sinaliza que, em termos de estudos críticos, os três autores podem ser considerados contemporâneos.

Na análise, é possível perceber que a categoria temática relativa à organização burocrática é predominante na produção de Prestes Motta. Porém, a categoria que se refere às temáticas ligadas à crítica do modo de produção capitalista e suas influências também tem papel de destaque. É importante sinalizar que o período compreendido entre 1988 e 1999 apresenta um nível de produção pequeno: uma das possíveis explicações é que, provavelmente, a plataforma utilizada para a coleta de dados não foi atualizada adequadamente pelos próprios autores. Essa situação será investigada de modo mais profundo no futuro.

O gráfico 3 apresenta a evolução histórica das categorias temáticas trabalhadas neste artigo na produção acadêmica de Garcia. 


\section{Gráfico 3}

\section{Evolução histórica em Garcia.}

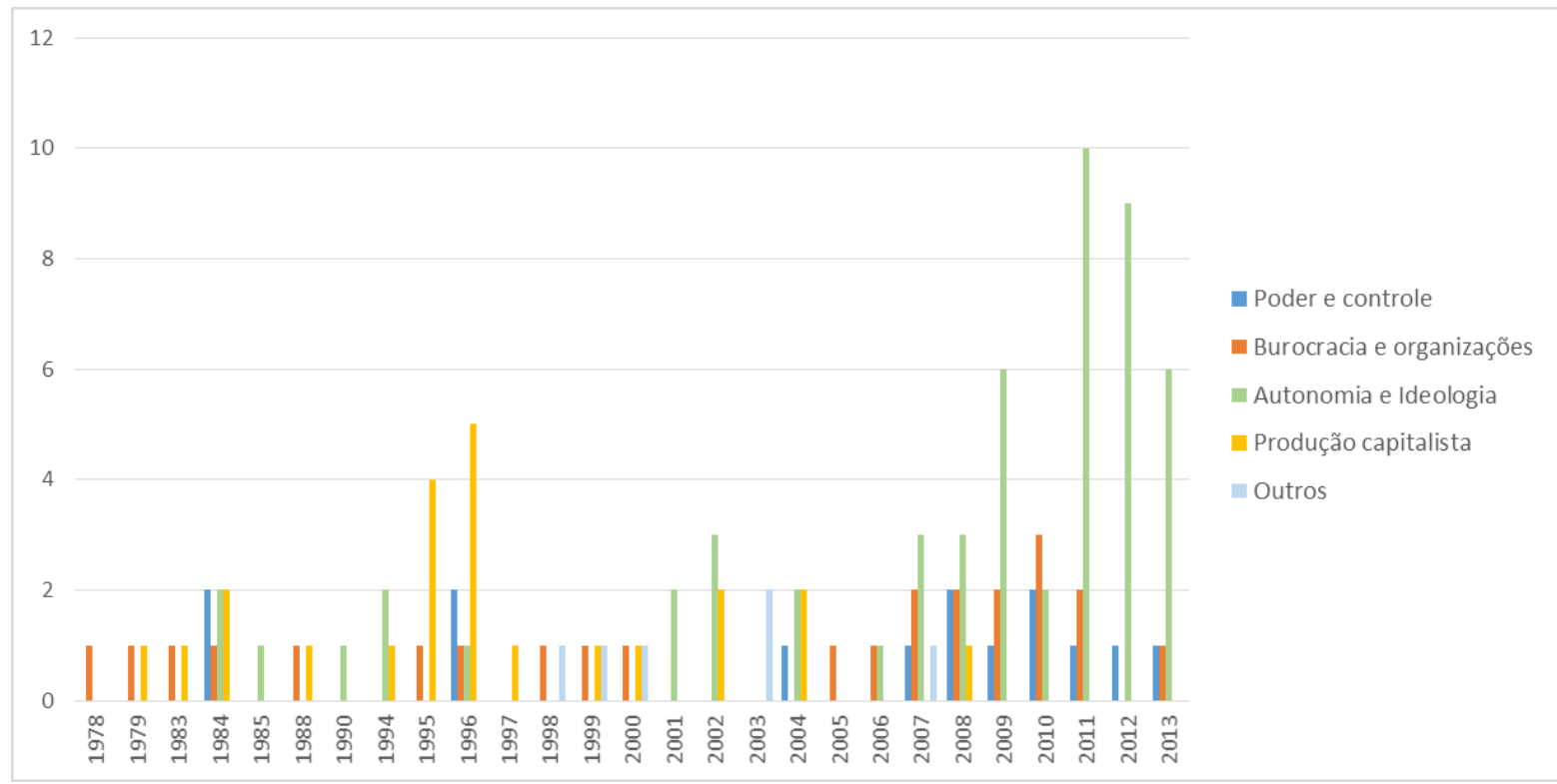

Fonte: Elaborada pelos autores.

A produção acadêmica de Garcia apresenta uma regularidade temática ao longo dos 35 anos analisados neste artigo. No entanto, é possível observar que as duas categorias mais recorrentes são Autonomia e Ideologia e Produção Capitalista. Essa situação, talvez, decorre da formação acadêmica de Garcia em Geografia na graduação, Administração no mestrado, Ciência Política no doutorado e Sociologia do Trabalho no pósdoutorado, que, em tese, o habilitaria a trabalhar temáticas abrangentes, que envolvem tanto a Autonomia e Ideologia e a Produção Capitalista.

Vale ressaltar que, nos últimos 10 anos, a categoria Autonomia e Ideologia se torna preponderante sobre as demais e acompanha o enfoque nos aspectos relacionados ao sofrimento no trabalho observado em suas publicações recentes. Os motivos ligados a essa reorientação temática serão mais bem investigados em futura fase qualitativa da pesquisa.

O gráfico 4 apresenta a evolução histórica das publicações de Faria. 


\section{Gráfico 4}

\section{Evolução histórica em Faria.}

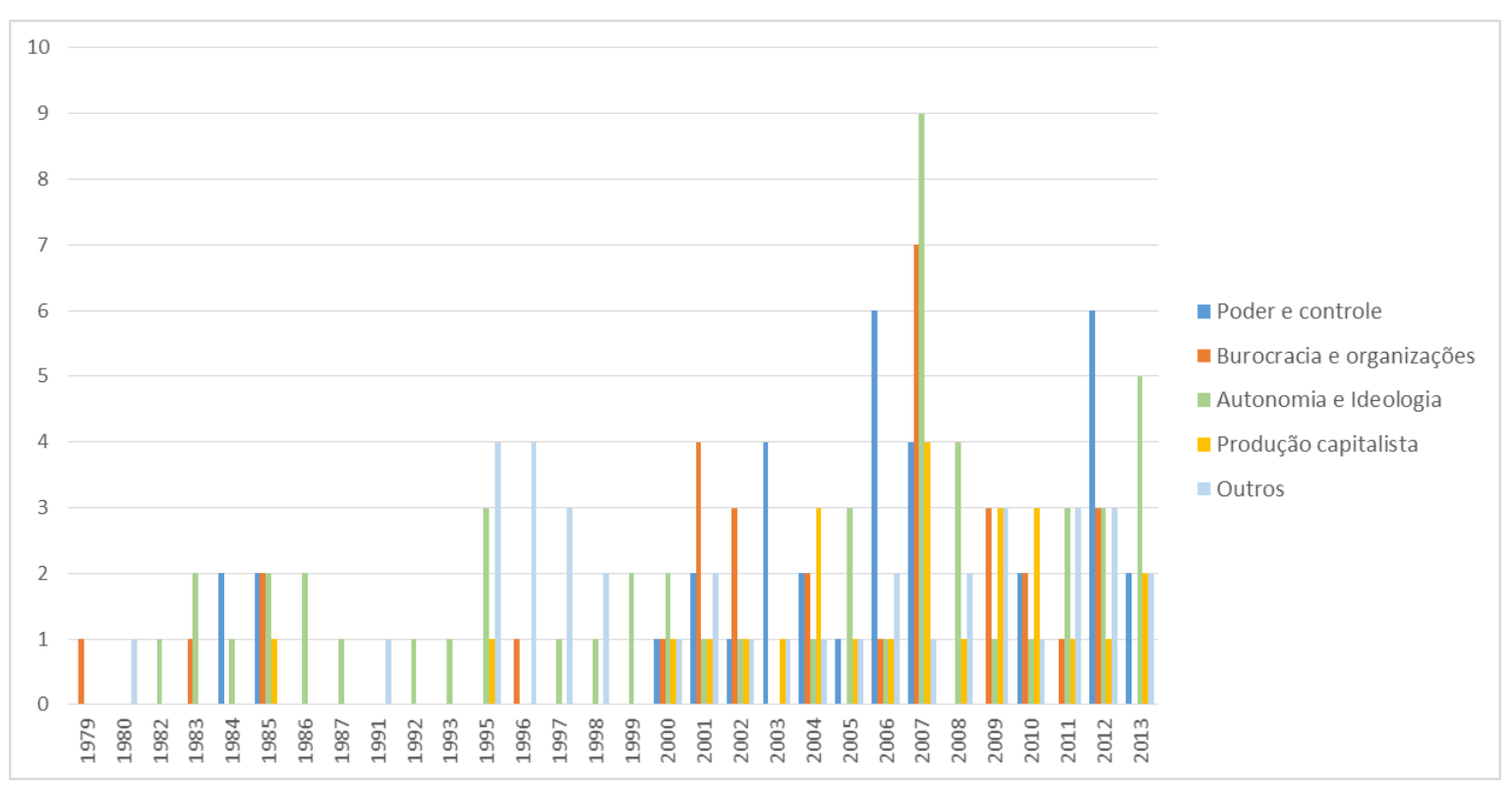

Fonte: Elaborada pelos autores.

A produção acadêmica de Faria também demonstra regularidade, no entanto, há maior diversificação que a observada na produção dos pesquisadores já analisados. Pode-se observar que a temática Autonomia e Ideologia é a que apresenta maior regularidade. A categoria "Outros" também se distribui de maneira regular e sinaliza que Faria produz ao longo dos anos uma sequência de obras que visam a realizar a reflexão de determinado assunto e/ou prática metodológica que vem recebendo maior atenção dos pesquisadores na área de organizações.

Além disso, pode-se perceber que a temática ligada a Poder e Controle, embora apareça em seus trabalhos pioneiros e percorra toda a sua produção, tem maior destaque na última década analisada, indicando uma concentração em trabalhos que pesquisam as relações de poder e controle na gestão do processo de trabalho nas organizações produtivas. A formação acadêmica concentrada nas áreas de Economia e Administração e seu pós-doutorado em Labor Relations direcionam as pesquisas realizadas por Faria para as relações de trabalho no interior das organizações produtivas, bem como aos desdobramentos externos que tais relações e as decorrentes práticas geram no contexto social e na organização e gestão do processo de trabalho.

A Tabela 1 apresenta o resumo das classificações de categorias temáticas trabalhadas por Tragtenberg, atribuídas aos artigos quando consideradas as produções dos três pesquisadores analisados neste artigo de maneira combinada. 
Tabela 1

Distribuição total de categorias

\begin{tabular}{|l|l|l|}
\hline \multicolumn{1}{|c|}{ Categorias } & \multicolumn{1}{|c|}{ Absoluto } & \multicolumn{1}{c|}{$\%$} \\
\hline Poder e controle & 61 & $16 \%$ \\
\hline Burocracia e organizações & 95 & $24 \%$ \\
\hline Autonomia e ideologia & 119 & $31 \%$ \\
\hline Produção capitalista & 62 & $16 \%$ \\
\hline Outros & 51 & $13 \%$ \\
\hline Total & 388 & $100 \%$ \\
\hline
\end{tabular}

Fonte: Elaborada pelos autores.

No contexto total, foram realizadas 388 classificações relativas às publicações analisadas. A categoria predominante foi Autonomia e Ideologia, demonstrando que os pesquisadores analisados apresentam forte preocupação com as condições de trabalho e de alienação do trabalhador dentro dos ambientes organizacionais. A segunda categoria mais observada foi Burocracia e Organizações, sinalizando que as abordagens referentes aos aspectos racionais, formais e estruturais representam um tema de interesse recorrente nas obras acadêmicas dos autores e também demonstra que todo o trabalho realizado por Tragtenberg na análise das organizações burocráticas continua reverberando por meio do trabalho desenvolvido pelos autores analisados.

É importante relembrar que as categorias trabalhadas neste artigo foram construídas para facilitar o acompanhamento didático das principais temáticas trabalhadas por Tragtenberg. De modo algum representam a totalidade das temáticas trabalhadas por ele e pelos pesquisadores estudados nem representam a totalidade das temáticas trabalhadas na área de Estudos Organizacionais críticos brasileiros.

O Gráfico 5 apresenta o comportamento geral das categorias temáticas trabalhadas por Tragtenberg quando consideradas as produções dos três pesquisadores analisados no artigo de maneira combinada.

\section{Gráfico 5}


Evolução histórica das categorias tragtenbergianas.

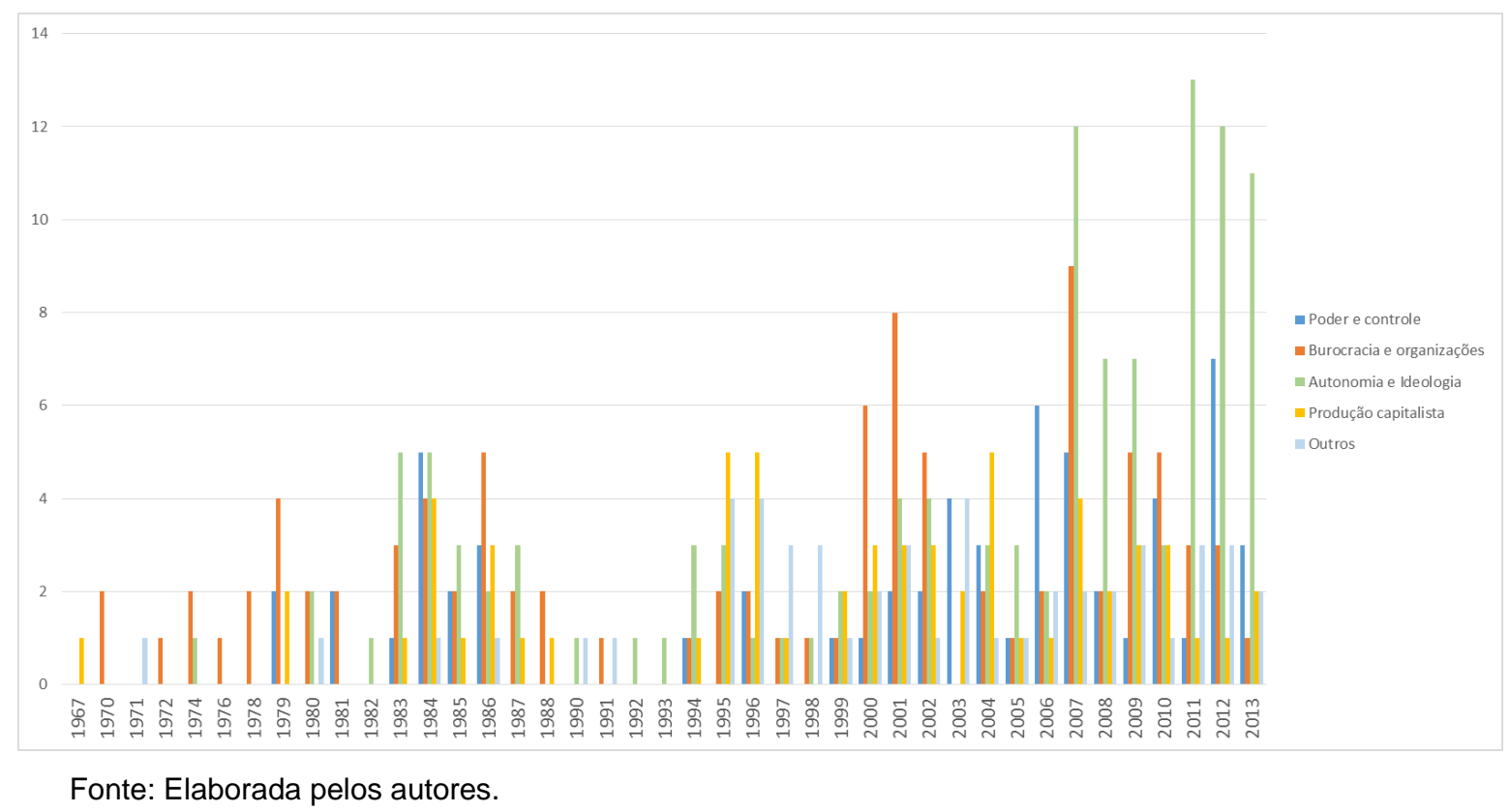

A representação visual da evolução histórica das categorias trabalhadas aqui demonstra que as duas categorias predominantes (Autonomia e Ideologia e Burocracia e Organizações) não estão concentradas em períodos específicos de pico de produção acadêmica, mas, sim, por serem categorias recorrentemente trabalhadas pelos autores analisados aqui. Essa situação reforça a tese da influência de Tragtenberg na produção acadêmica dos autores trabalhados neste artigo.

Também é possível observar que as publicações tiveram um momento de alta no período entre 1983 e 1986 e depois voltaram a assumir um viés de alta a partir de 1995, que se sustenta até o momento, devido ao trabalho dos pesquisadores José Henrique de Faria e Fernando Coutinho Garcia na área acadêmica dos Estudos Organizacionais críticos brasileiros.

\section{Conclusão}

A partir do estudo apresentado aqui, pode-se perceber que a influência de Tragtenberg na produção acadêmica dos pesquisadores analisados neste artigo é significativa. Esse resultado corrobora o estudo de Paes de Paula (2008) que já havia identificado Maurício Tragtenberg como pioneiro no desenvolvimento de temáticas críticas em Estudos Organizacionais no Brasil. No entanto, vai além, delimitando um grupo de autores/pesquisadores que escreveu sob sua influência, isto é, Fernando Prestes Motta, José Henrique de Faria e Fernando Coutinho Garcia, de acordo com as informações tratadas aqui, que pode ser denominada a primeira geração de pesquisadores de orientação crítica de influência tragtenbergiana em Estudos Organizacionais brasileiros.

Em certa medida, essa primeira geração trabalha com as categorias tragtenbergianas durante todo o seu período produtivo (que ainda continua para Faria e Coutinho Garcia). No entanto, foi possível demonstrar que as categorias se encaixam em seus interesses individuais de pesquisa e vão conferindo forma às produções acadêmicas que constituem referência na análise e no estudo de organizações no Brasil. Todos os três autores influenciaram dezenas de pesquisadores sob sua orientação direta e indireta, formando uma massa crítica que auxilia a manutenção e ampliação do campo de Estudos Organizacionais críticos. O trabalho conjunto possibilita que essa área crítica cumpra o papel de ponderar e refletir sobre os 
direcionamentos e sobre as pesquisas que não consideram os aspectos ideológicos e encobertos, intencionalmente ou não, na realidade organizacional.

Ressaltamos, uma vez mais, que a intenção deste artigo não é apontar produções superiores ou preponderantes na área, mas, sim, demonstrar por meio de suas produções acadêmicas que os três pesquisadores analisados são contemporâneos no tratamento das questões críticas no estudo das organizações. Contemporâneos significa que eles se influenciaram mutuamente e produziram pesquisas de modo simultâneo, mas, principalmente, significa que todos receberam a influência majoritária de Tragtenberg.

Hoje, a tradição de pesquisa que Tragtenberg iniciou representa uma parcela pequena, em termos quantitativos, da vasta área acadêmica da Administração. No entanto, atualmente, a importância da crítica assume um significado cada vez maior perante os desdobramentos da produção acadêmica em Estudos Organizacionais sem reflexão ou acrítica, sinalizada por diferentes autores em revisões bibliométricas e/ou analíticas da área (VERGARA e PINTO, 2001; RODRIGUES e CARRIERI, 2001; CRUBELLATE, 2005; FARIA e MENEGHETTI, 2010). Desse modo, a postura da pesquisa crítica mostra-se necessária para influenciar os desenvolvimentos futuros do campo acadêmico de Estudos Organizacionais, pois, nesse caso, como Tragtenberg (1991, p. 9) já dizia: "influenciar é ter poder".

\section{Referências}

ANTUNES, R. Maurício Tragtenberg: a perda de um intelectual herético. In: SILVA, A. D.; MARRACH, S. A. Maurício Tragtenberg: uma vida para as ciências humanas. São Paulo: Ed. Unesp, 2001. 97-102 p.

CRUBELlATE, J. M. Estudos organizacionais no Brasil: do futuro que queremos e do futuro que teremos. Cad. EBAPE.BR, v. 3, n. 4, p. 01-04, 2005.

FARIA, J. H. Tecnologia e processo de trabalho. Curitiba: Ed. UFPR, 1992. v. 1.

FARIA, J. H. Teoria crítica em estudos organizacionais no Brasil: o estado da arte. Cad. EBAPE.BR, v. 7, n. 3, p. 509$515,2009$.

FARIA, J. H.; MENEGHETTI, F. K. (Sem) saber e (com) poder nos estudos organizacionais. Cadernos EBAPE.BR, v. 8 , n. 1 , p. 38-52, 2010.

MATTOS, P. L. C. L. Bibliometria: a metodologia acadêmica convencional em questão. RAE eletrônica, v. 3, n. 2, dez. 2004.

MENEGHeTti, F. K. Trabalho e Educação Em Maurício Tragtenberg. (Tese de Doutorado). Programa de PósGraduação em Educação Universidade Federal do Paraná. Curitiba, 2009.

MOTTA, F. Teoria geral da administração: uma introdução. São Paulo: Pioneira, 2001.

PAES DE PAULA, A. P. Maurício Tragtenberg: contribuições de um marxista anarquizante para os estudos organizacionais críticos. Rev. Adm. Pública, v. 42, n. 5, p. 949-968, 2008.

PAES DE PAULA, A. P. et al. A tradição e a autonomia dos Estudos Organizacionais Críticos no Brasil. Revista de Administração de Empresas, v. 50, n. 1, p. 10-23, mar. 2010.

RODRIGUES, S. B.; CARRIERI, A. P. A tradição anglo-saxônica nos estudos organizacionais brasileiros. Revista de Administração Contemporânea, v. 5, n. Edição especial, p. 81-102, 2001.

SILVA, D. A.; MARRACH, S. Maurício Tragtenberg: uma vida para as ciências humanas. São Paulo: Ed. Unesp, 2001. 
TRAGTENBERG, M. Planificação: desafio o século XX. São Paulo: Senzala, 1967.

TRAGTENBERG, M. Burocracia e ideologia. São Paulo: Ática, 1974.

TRAGTENBERG, M. Administração, poder e ideologia. São Paulo: Moraes, 1980.

TRAGTENBERG, M. Reflexões sobre o socialismo. São Paulo: Moderna, 1986.

TRAGTENBERG, M. Administração, poder e ideologia. São Paulo: Cortez, 1989.

TRAgtenberg, M. Memorial. Revista Pro-Posições, n. 4, p. 79-87, mar. 1991.

TRAGTENBERG, M. Sobre educação, política e sindicalismo. São Paulo: Editora UNESP, 2004.

VANTI, N. A. P. Da bibliometria à webometria: uma exploração conceitual dos mecanismos utilizados para medir o registro da informação e a difusão do conhecimento. Ciência da Informação, v. 31, n. 2, p. 369-379, ago. 2002.

VERGARA, S. C.; PINTO, M. C. S. Referências teóricas em análise organizacional: um estudo das nacionalidades dos autores referenciados na literatura brasileira. Revista de Administração Contemporânea, v. 5, n. Edição especial, p. 103-121, 2001. 